\title{
PEMODELAN JARING-JARING MAKANAN PEMANGSA GENERALIS PADA DUA TROFIK
}

\author{
SYED ABDUL JABAR ${ }^{1}$, MAHDHIVAN SYAFWAN ${ }^{* *}$, AADREAN $^{2}$ \\ ${ }^{1}$ Jurusan Matematika FMIPA Universitas Andalas, Padang, Indonesia \\ ${ }^{2}$ Jurusan Biologi FMIPA Universitas Andalas, Padang, Indonesia \\ *email : mahdhivan@sci.unand.ac.id
}

Diterima 12 Juni 2021 Direvisi 22 Juni 2021 Dipublikasikan 26 Juli 2021

\begin{abstract}
Abstrak. Trofik merupakan tingkatan yang menggambarkan cara suatu spesies memperoleh energi dari lingkungan. Jalur perpindahan energi dari trofik yang satu ke trofik yang lain dikenal sebagai rantai makanan yang kemudian saling menjalin menjadi jaring-jaring makanan. Dalam makalah ini dibahas pemodelan matematika jaring-jaring makanan dua trofik pada pemangsa generalis, yaitu pemangsa yang dapat memakan beberapa jenis mangsa. Model ini dikembangkan berdasarkan model mangsa pemangsa Lotka-Volterra. Model yang dikaji kemudian diimplementasikan pada kasus jaring-jaring makanan dua trofik antara singa sebagai pemangsa, dengan kambing wildebeest dan zebra sebagai mangsa di Taman Nasional Kruger, Afrika Selatan. Hasil numerik menunjukkan bahwa singa, kambing wildebeest dan zebra dapat terus hidup berdampingan dan mencapai keseimbangan ekologi.
\end{abstract}

Kata Kunci: Persamaan diferensial, Lotka-Volterra, jaring-jaring makanan, pemangsa generalis, dua trofik

\section{Pendahuluan}

Dalam ekologi, lingkungan terdiri dari dua komponen, yaitu biotik dan abiotik. Komponen biotik adalah segala sesuatu yang hidup, seperti mikro organisme, tumbuhan, hewan, dan manusia. Komponen abiotik adalah segala sesuatu yang tidak hidup, seperti air, tanah, udara dan lainnya. Faktor biotik dan abiotik saling berinteraksi satu sama lain sehingga mempengaruhi kelangsungan hidup masing-masing organisme, populasi atau komunitas, seperti proses pertumbuhan dan perkembangannya $[6]$.

Suatu komunitas dalam biologi dapat dikelompokkan ke dalam trofik, yaitu tingkatan yang menggambarkan cara memperoleh energi dari lingkungan. Trofik pertama dikenal sebagai produsen primer, trofik kedua disebut konsumen primer yang memperoleh energi dari trofik pertama, dan trofik ketiga disebut konsumen sekunder yang memperoleh energi dari trofik kedua. Beberapa komunitas memiliki 
spesies dengan trofik yang lebih tinggi [6]. Jalur perpindahan energi dari trofik yang satu ke trofik yang lain dikenal sebagai rantai makanan. Hubungan makan-memakan umumnya saling menjalin menjadi jaring-jaring makanan [6]. Dalam jaring-jaring makanan tentu saja terdapat berbagai jenis hubungan antar spesies. Ada spesies yang bersaing dengan spesies lain dalam mendapatkan makanan (kompetisi), ada juga spesies yang dapat hidup berdampingan dengan baik dengan spesies lain (koeksistensi). Memahami koeksistensi spesies menjadi salah satu hal yang paling menantang bagi ahli ekologi. Beberapa ilmuwan telah membahas bagaimana keragaman spesies berkaitan dengan koeksistensi dalam suatu komunitas [4].

Kivan telah membahas empat model jaring-jaring makanan dengan banyak spesies. Jaring-jaring makanan yang dipertimbangkan oleh Kivan lebih kompleks jika dibandingkan dengan model jaring-jaring makanan sederhana yang biasanya terdiri dari 2 sampai 4 spesies [4]. Dalam model yang dikembangkan oleh Kivan terdapat dua tipe pemangsa, yaitu pemangsa generalis dan pemangsa spesialis. Pemangsa generalis adalah pemangsa yang dapat memakan beberapa jenis mangsa. Sebaliknya, pemangsa spesialis adalah pemangsa yang hanya memangsa spesies tertentu.

Dalam makalah ini dibahas pemodelan jaring-jaring makanan pemangsa generalis pada dua trofik berdasarkan kajian yang dilakukan oleh Kivan [4]. Model ini dikembangkan dari model mangsa pemangsa Lotka-Volterra. Selanjutnya, model yang dikaji akan diimplementasikan pada kasus jaring-jaring makanan dua trofik antara singa sebagai pemangsa, dengan kambing wildebeest dan zebra sebagai mangsa di Taman Nasional Kruger, Afrika Selatan. Kasus interaksi mangsa-pemangsa pada ketiga hewan ini juga pernah dibahas oleh Fay dan Greeff [2] dengan menggunakan model yang berbeda dan meninjau beberapa skenario.

\section{Review Model Lotka-Volterra}

Salah satu contoh interaksi dalam suatu ekosistem adalah mangsa-pemangsa ( preypredator). Berikut dijelaskan penurunan model mangsa-pemangsa yang diambil dari referensi [3].

Misalkan jumlah populasi pemangsa pada waktu $t$ adalah $y(t)$ dan jumlah populasi mangsa pada waktu $t$ adalah $x(t)$. Dalam hal ini diasumsikan bahwa populasi mangsa adalah satu-satunya pasokan makanan bagi pemangsa. Jika tidak ada pemangsa, maka populasi mangsa diasumsikan bertumbuh secara eksponensial, yaitu $\frac{d x}{d t}=a x$, dimana $a$ menyatakan tingkat kelahiran alami mangsa. Ketika pemangsa ada, diasumsikan populasi mangsa berkurang pada tingkat yang sebanding dengan dikonsumsinya mangsa oleh pemangsa. Salah satu model sederhana untuk hal ini adalah $\frac{d x}{d t}=-b x y$. Jadi, model laju perubahan untuk populasi mangsa adalah $\frac{d x}{d t}=a x-b x y$.

Untuk populasi pemangsa dibuat asumsi yang berlawanan. Dengan tidak adanya mangsa, populasi pemangsa diasumsikan menurun pada tingkat yang sebanding dengan populasi saat itu. Jadi ketika $x=0$ maka $\frac{d y}{d t}=-c y$, dimana $c$ menyatakan tingkat kematian alami pemangsa. Akibatnya, spesies pemangsa akan punah saat 
kasus tidak ada mangsa. Ketika ada mangsa, diasumsikan populasi pemangsa akan meningkat pada tingkat yang sebanding dengan pertumbuhan pemangsa karena mengkonsumsi mangsa, atau dimodelkan dengan $\frac{d y}{d t}=d x y$. Jadi model laju perubahan untuk populasi pemangsa adalah $\frac{d y}{d t}=-c y+d x y$. Dengan demikian sistem mangsa-pemangsa dimodelkan sebagai berikut:

$$
\begin{aligned}
& \frac{d x}{d t}=a x-b x y \quad=x(a-b y), \\
& \frac{d y}{d t}=-c y+d x y \quad=y(-c+d x),
\end{aligned}
$$

dimana parameter $a, b, c$, dan $d$ diasumsikan positif. Karena berhubungan dengan jumlah populasi, maka $x, y \geq 0$. Sistem mangsa-pemangsa ini biasanya dikenal dengan model Lotka-Volterra [3]. Model ini diperkenalkan oleh Lotka pada tahun 1925 dan Volterra pada tahun 1926.

\section{Jaring-Jaring Makanan Dua Trofik}

Dalam biologi dikenal adanya istilah komunitas, yaitu sekumpulan berbagai macam populasi makhluk hidup yang hidup dalam suatu wilayah tertentu. Suatu komunitas tersusun dari semua populasi yang hidup dan saling berinteraksi antara satu dengan yang lain dalam suatu wilayah dan waktu tertentu. Suatu komunitas dapat dikelompokkan ke dalam trofik, yaitu tingkatan yang menggambarkan cara memperoleh energi dari lingkungan [6]. Trofik pertama dikenal sebagai produsen primer, yaitu organisme yang memperoleh energi langsung dari matahari. Contoh dari trofik pertama adalah tumbuhan. Trofik kedua diduduki oleh herbivora yang memakan tumbuhan, biasanya disebut konsumen primer. Trofik ketiga diduduki oleh karnivora yang memakan herbivora, biasanya disebut konsumen sekunder. Beberapa komunitas memiliki karnivora dengan trofik yang lebih tinggi [6].

Jalur perpindahan energi dari trofik yang satu ke trofik yang lain dikenal sebagai rantai makanan. Hubungan makan-memakan umumnya saling menjalin menjadi jaring-jaring makanan [6]. Gambar $1 \mathrm{~A}$ dan $1 \mathrm{~B}$ adalah ilustrasi jaring-jaring makanan dua trofik, sedangkan Gambar $1 \mathrm{C}$ dan $1 \mathrm{D}$ adalah ilustrasi jaring-jaring makanan tiga trofik. Gambar $1 \mathrm{~A}$ dan $1 \mathrm{C}$ menunjukkan ilustrasi jaring-jaring makanan dengan pemangsa generalis, yaitu pemangsa yang dapat memakan beberapa jenis mangsa. Gambar $1 \mathrm{~B}$ dan $1 \mathrm{D}$ menunjukkan ilustrasi jaring-jaring makanan dengan pemangsa spesialis, yaitu pemangsa yang hanya memangsa spesies tertentu.

Dalam makalah ini, model jaring-jaring makanan dua trofik dengan pemangsa generalis diilustrasikan pada Gambar 1 A. Seperti yang terlihat pada Gambar 1 A, perpindahan energi hanya terjadi pada dua trofik saja. Artinya, perpindahan energi bisa saja terjadi dari organisme yang menduduki trofik kedua (herbivora) ke organisme yang menduduki trofik ketiga (karnivora) atau dari trofik ketiga (karnivora) ke trofik keempat (karnivora), dan seterusnya. Contoh dari jaring-jaring makanan dua trofik dengan pemangsa yang generalis adalah sebagai berikut [6]:

(1) Harimau (Panthera tigris) memakan babi hutan, rusa, kancil, dan hewan ternak. 

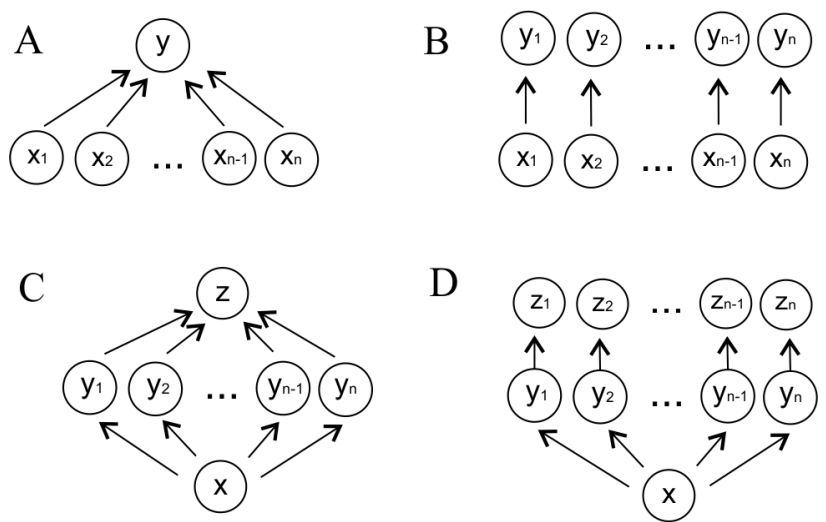

Gambar 1. Jaring-jaring makanan dua trofik dengan pemangsa generalis (A) dan spesialis (B), serta tiga trofik dengan pemangsa generalis (C) dan spesialis (D)[4]

(2) Elang-ular bido (Spilornis cheela) memakan berbagai jenis ular, kadal, burung, dan katak.

(3) Berang-berang (Aonyx cinereus) memakan ikan, katak, siput, dan serangga.

Contoh dari pemangsa spesialis adalah kucing lynx Kanada (Lynx canadensis) yang memangsa kelinci sepatu salju (Lepus americanus) [6].

\section{Konstruksi Model Jaring-Jaring Makanan Dua Trofik pada Pemangsa Generalis}

Pada jaring-jaring makanan dua trofik dari trofik kedua ke trofik ketiga, terdapat spesies yang menjadi pemangsa (karnivora) dan spesies yang menjadi mangsa (herbivora). Dalam bab ini akan dibahas penurunan model matematika jaring-jaring makanan dua trofik pada pemangsa generalis [lihat kembali Gambar $1 \mathrm{~A}$ ].

Misalkan $y(t)$ dan $x_{i}(t)$ masing-masing menyatakan jumlah populasi pemangsa dan jumlah populasi mangsa spesies ke- $i$ pada waktu $t$, dengan $i=1,2, \cdots, n$. Ketika ada mangsa, populasi pemangsa akan meningkat pada tingkat yang sebanding dengan pertumbuhan pemangsa karena mengkonsumsi mangsa. Disini tingkat pertumbuhan populasi pemangsa diasumsikan dipengaruhi oleh preferensi pemangsa terhadap mangsa spesies ke- $i$, dinotasikan dengan $u_{i}$. Dalam hal ini, $u_{i}$ dapat diartikan seberapa suka pemangsa memakan mangsa spesies ke- $i$. Hal lain yang mempengaruhi pertumbuhan populasi pemangsa adalah tingkat pertemuan dan penangkapan mangsa spesies ke- $i$, dinotasikan dengan $\lambda_{i}$. Jadi laju pertumbuhan untuk populasi pemangsa dapat dimodelkan sebagai berikut:

$$
\begin{aligned}
\frac{d y}{d t} & =u_{1} \lambda_{1} x_{1} y+u_{2} \lambda_{2} x_{2} y+\cdots+u_{n} \lambda_{n} x_{n} y \\
& =y \sum_{i=1}^{n} u_{i} \lambda_{i} x_{i} .
\end{aligned}
$$

Kemudian berdasarkan model Lotka-Volterra, laju penurunan populasi pemangsa diasumsikan dipengaruhi oleh tingkat kematian alami pemangsa, misalkan 
dinotasikan dengan $m$. Hal ini disebabkan ketika tidak ada mangsa maka populasi pemangsa akan turun. Dengan demikian, model laju perubahan untuk populasi pemangsa adalah

$$
\frac{d y}{d t}=y \sum_{i=1}^{n} u_{i} \lambda_{i} x_{i}-m y .
$$

Selanjutnya untuk model pertumbuhan populasi mangsa, diasumsikan bahwa setiap mangsa tidak saling bersaing dalam mendapatkan makanan. Ketika tidak ada pemangsa, populasi masing-masing mangsa diasumsikan tumbuh secara logistik sebagai berikut:

$$
\frac{d x_{i}}{d t}=r_{i}\left(1-\frac{x_{i}}{K_{i}}\right) x_{i},
$$

dimana $r_{i}$ adalah tingkat pertumbuhan populasi mangsa spesies ke- $i$ dan $K_{i}$ adalah kapasitas daya dukung mangsa spesies ke- $i$. Ketika ada pemangsa, populasi mangsa spesies ke- $i$ diasumsikan akan turun dengan tingkat yang sebanding dengan pertemuan dan penangkapan mangsa spesies ke- $i$ oleh pemangsa dan juga tingkat kesukaan pemangsa memakan mangsa spesies ke- $i$, sehingga model laju perubahan untuk populasi mangsa menjadi

$$
\frac{d x_{i}}{d t}=r_{i} x_{i}\left(1-\frac{x_{i}}{K_{i}}\right)-\lambda_{i} u_{i} x_{i} y .
$$

Persamaan (4.2) dan (4.4) merupakan sistem persamaan diferensial yang membentuk model jaring-jaring makanan dua trofik pada pemangsa generalis, yaitu

$$
\begin{aligned}
\frac{d x_{i}}{d t} & =r_{i} x_{i}\left(1-\frac{x_{i}}{K_{i}}\right)-\lambda_{i} u_{i} x_{i} y, i=1,2, \cdots, n, \\
\frac{d y}{d t} & =y \sum_{i=1}^{n} u_{i} \lambda_{i} x_{i}-m y,
\end{aligned}
$$

dimana

$x_{i}=$ jumlah populasi mangsa spesies ke $-i$ pada waktu $t$,

$y=$ jumlah populasi pemangsa pada waktu $t$,

$r_{i}=$ tingkat pertumbuhan populasi mangsa spesies ke- $i$,

$K_{i}=$ kapasitas daya dukung mangsa spesies ke-i,

$\lambda_{i}=$ tingkat pertemuan dan penangkapan mangsa spesies ke-i,

$u_{i}=$ tingkat kesukaan pemangsa memangsa spesies ke $-i$,

$m=$ tingkat kematian alami pemangsa.

Semua parameter di atas ditetapkan bernilai positif.

\section{Contoh Implementasi}

Pada bagian ini model (4.5) diimplementasikan pada kasus jaring-jaring makanan dua trofik antara singa sebagai pemangsa (trofik ketiga) dengan kambing wildebeest dan zebra sebagai mangsa (trofik kedua) di Taman Nasional Kruger. Taman 
Nasional Kruger terletak di ujung selatan Afrika Selatan pada perbatasan internasional antara Afrika Selatan dan Mozambik [2].

Taman Nasional Kruger sangat cocok untuk berbagai spesies pemakan rumput dan mampu memelihara sekitar 12.000 kambing wildebeest (Connochaetes taurius) dan 12.000 zebra (Equus burchelli) [5]. Berbagai spesies pemangsa juga terdapat di Taman Nasional Kruger, namun singa (Panthera leo) memiliki pengaruh yang lebih besar terhadap jumlah populasi kambing wildebeest dan zebra [1].

Selama musim kemarau pada tahun 1969-1972, populasi kambing wildebeest dan zebra di Taman Nasional Kruger harus dipangkas karena penggunaan lahan yang berlebihan. Pemangkasan populasi zebra dilakukan lebih sering dan lebih lama. Ketika program pemangkasan ini dihentikan pada tahun 1972 setelah musim hujan lebat, populasi zebra menurun selama beberapa periode seperti yang diharapkan, namun kembali naik menuju jumlah yang relatif tetap. Sedangkan populasi kambing wildebeest terus menurun meskipun lahan telah kembali hijau oleh rerumputan. Pada tahun 1975, pemangkasan populasi singa dilakukan agar populasi kambing wildebeest bisa kembali naik. Kemudian, pada tahun 1982 pemangkasan populasi singa dihentikan karena populasi kambing wildebeest dan zebra sudah naik kembali.

Dalam [2] telah dibahas beberapa model mangsa-pemangsa untuk ketiga hewan di atas dengan berbagai skenario. Pada bab ini, studi pada [2] dikaji kembali dengan menggunakan model (4.5) untuk kasus khusus $n=2$. Dalam hal ini, misalkan $x_{1}(t)$ adalah jumlah populasi kambing wildebeest pada waktu $t, x_{2}(t)$ adalah jumlah populasi zebra pada waktu $t$, dan $y(t)$ adalah jumlah populasi singa pada waktu t. Nilai-nilai parameter yang digunakan sama dengan yang dipakai pada [2], yaitu sebagaimana disajikan dalam Tabel 1.

Tabel 1. Nilai-nilai parameter [2].

\begin{tabular}{|c|c|c|c|}
\hline Parameter & Kambing Wildebeest $(i=1)$ & Zebra $(i=2)$ & Singa \\
\hline$r_{i}$ & 0,405 & 0,35 & - \\
\hline$m$ & - & - & 1,5 \\
\hline$\lambda_{i}$ & 0,81 & 0,75 & - \\
\hline$u_{i}$ & 0,28 & 0,19 & - \\
\hline$K_{i}$ & 12 & 12 & - \\
\hline
\end{tabular}

Dengan menggunakan nilai-nilai parameter seperti pada Tabel 1, model (4.5) untuk $n=2$ menjadi:

$$
\begin{aligned}
\frac{d x_{1}}{d t} & =0,405 x_{1}\left(1-\frac{x_{1}}{12}\right)-0,2268 x_{1} y, \\
\frac{d x_{2}}{d t} & =0,35 x_{2}\left(1-\frac{x_{2}}{12}\right)-0,1425 x_{2} y, \\
\frac{d y}{d t} & =y\left[0,2268 x_{1}+0,1425 x_{2}\right]-1,5 y .
\end{aligned}
$$

Nilai awal populasi dipilih berdasarkan data sensus tahun 1972 [2], yaitu 10.600 populasi kambing wildebeest, 10.500 populasi zebra, dan 500 populasi singa, atau 
ditulis (dalam ribuan)

$$
x_{1}(0)=10,6, x_{2}(0)=10,5, \text { dan } y(0)=0,5 .
$$

Alasan pemilihan nilai awal ini karena pada akhir tahun 1972 program pemangkasan kambing wildebeest dan zebra dihentikan.

Sistem (5.1) dengan nilai awal (5.2) diselesaikan secara numerik dengan menggunakan software MATLAB. Kurva solusinya diberikan pada Gambar 2. Dari Gambar 2 dapat dilihat bahwa pada saat-saat awal, populasi singa, kambing wildebeest dan zebra mengalami osilasi yang cukup besar. Ketika populasi singa naik, maka pada saat yang bersamaan populasi kambing wildebeest dan zebra cenderung menurun. Ketika pasokan makanan untuk singa terus menurun, maka populasi singa juga akan menurun. Kemudian ketika kehadiran singa terus berkurang, pada saat yang bersamaan populasi kambing wildebeest dan zebra cenderung naik kembali. Pada saat populasi kambing wildebeest dan zebra naik, maka populasi singa juga akan naik, dan begitu seterusnya.

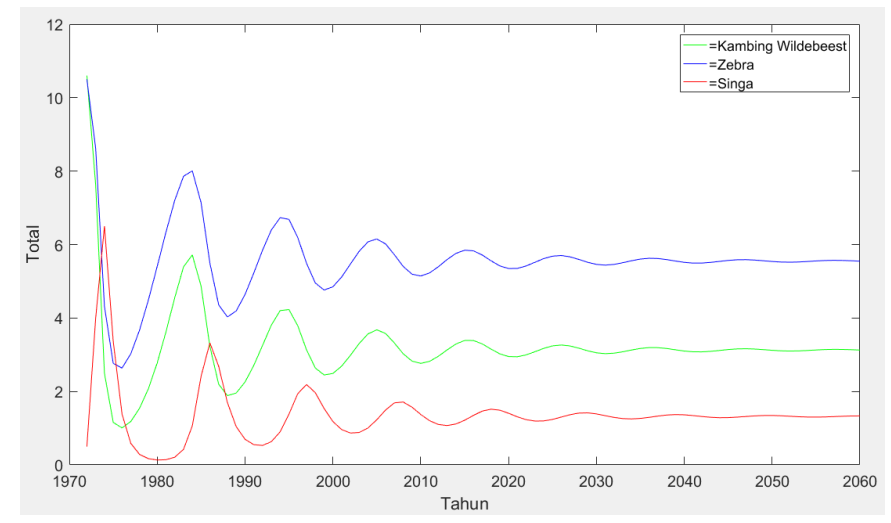

Gambar 2. Kurva solusi numerik dari sistem (5.1) dengan nilai awal (5.2).

Seiring berjalannya waktu, osilasi yang terjadi pada populasi ketiga hewan tersebut semakin lama semakin mengecil dan masing-masingnya menuju ke satu nilai. Berdasarkan hasil ini, maka dapat disimpulkan bahwa ketiga hewan ini dapat terus hidup berdampingan dan mencapai keseimbangan ekologi.

\section{Kesimpulan}

Dalam makalah ini telah dibahas penurunan model jaring-jaring makanan dua trofik pada pemangsa generalis yang dikembangkan berdasarkan konsep model LotkaVolterra. Model ini kemudian diimplementasikan pada kasus jaring-jaring makanan dua trofik pada singa, kambing wildebeest, dan zebra di Taman Nasional Kruger, Afrika Selatan. Berdasarkan hasil numerik, masing-masing jumlah populasi ketiga hewan tersebut menuju ke satu nilai. Hal ini menyimpulkan bahwa singa, kambing wildebeest, dan zebra di Taman Nasional Kruger dapat terus hidup berdampingan 
dan mencapai keseimbangan ekologi. Hasil ini perlu dijustifikasi secara umum dengan melakukan analisis kestabilan pada model.

\section{Ucapan Terima kasih}

Penelitian ini didanai hibah Riset Dasar LPPM Universitas Andalas, dengan nomor kontrak T/49/UN.16.17/PT.01.03-IS-RD/2020. Penulis mengucapkan terimakasih kepada Jenizon, Des Welyyanti, dan Arrival Rince Putri atas masukan dan saran perbaikan dalam makalah ini.

\section{Daftar Pustaka}

[1] Bothma-D Preez, B.L.J. 1996. Game Range Management. J.L. van Schaik, Pretoria.

[2] Fay, T.H and J.C. Greeff. 2006. Lion, wildebeest and zebra: A predatorprey model. Ecological Modelling. 196: 237-244.

[3] Hirsch, M.W., S. Smale and R.L. Devaney. 2004. Differential Equations, Dynamical Systems, and An Introduction to Chaos. Elsevier Academic Press, New York.

[4] Kivan, V. 2014. Competition in di- and tri-trophic food web modules. Journal of Theoretical Biology. 343: 127137.

[5] Starfield, A.M., G.L. Smuts and J.D. Shiell. 1976. A simple wildebeest population model and its application. South African J. Wildlife Resour. 6(2): 9598.

[6] Urry, L.A., M.L. Cain, S.A. Wasserman, P.V. Minorsky, J.B. Reece and N.A. Campbell. 2011. Campbell Biology. Pearson, New York. 